Nicholeon, J. (ISM) Amiodarone and psychiatric symptoms (letter). British journal of Psychiotry. 175. $191-192$.

Roynolds, J. E. F. (1ss6) Mortindale: The Extro Pharmocopoeia. London: Royal Pharmaceutical Society.

A.T. Odelola Rawnsley Building, Manchester Royal Infirmary, Oxford Road, Manchester MI3 9WL

\section{Venlafaxine and paroxetine in treatment-resistant depression}

Sir: Poirier \& Boyer (1999) suggest their comparative trial showed some evidence of superiority of venlafaxine over paroxetine in treatment-resistant depression. Examining the previous antidepressants used throws considerable doubt on this conclusion.

Sixty-six per cent of the venlafaxine group and $65 \%$ of the paroxetine group had previously been treated with a selective serotonin reuptake inhibitor (SSRI). As venlafaxine is the only serotonin-noradrenaline reuptake inhibitor (SNRI) available, none of the patients will have previously taken an SNRI. Most of the patients in the study have already found one SSRI ineffective: we should not be surprised that paroxetine tended to be less helpful.

Although numbers would be small it would be interesting to examine response rates for the patients who had not been treated with an SSRI previously. I suspect a difference may not be apparent in this group.

Despite reservations, I note that the study does throw some light on a common clinical problem. Psychiatrists generally look to drugs of a different class when one medication has been unhelpful. This study supports this practice, at least in the use of venlafaxine rather than another SSRI when treatment with a first SSRI has failed.

Polrier, M. F. \& Eoyer, P. (ISs) Venlafaxine and parocetine in treatment-resistant depression. Doubleblind, randomised comparison. British journol of Psychiatry 175, 12-16.

J. Gregson Alfred Child and Adolescent Mental Health Service, 594 St Kilda Road. Melbourne, Victoria 3004, Australia

Authors' reply: In response to Dr Gregson, while approximately two-thirds of patients in the venlafaxine and paroxetine groups had received an SSRI previously, $69 \%$ of the venlafaxine group and $73 \%$ of the paroxetine group had also received a tricyclic antidepressant (TCA) previously. No differences in response were noted between treatment groups among patients previously treated with a TCA. Although not strictly considered as SNRIs, the TCAs exhibit a range of activity on serotonin, noradrenaline, or combined serotoninnoradrenaline reuptake.

We agree with Dr Gregson that the results of our study support the use of an antidepressant of a different pharmacological class in patients who have failed to respond to an SSRI.

M.-F. Poirler SHU-Centre Hospitalier SainteAnne, I rue Cabanis, 75674 Paris, France

P. Boyer Hôpital Pitié-Salpêtrière, Paris, France

\section{Urinary detection of olanzapine - an aid to compliance}

Sir: With increasing use of oral atypical antipsychotic drugs and the current absence of injectable preparations, it is to be expected that the use of depot medication will decline (Liberman, 1988). With this comes the increased importance of ensuring patient compliance with medication.

Previous analysis of serum olanzapine levels has primarily been concerned with the pharmacokinetics and clinical response to particular levels (Perry et al, 1997; Prieto et al, 1997; Berna et al, 1998), and these results are, as yet, not useful for everyday clinical practice.

We report that in a carefully selected group of patients, monitoring of the presence or absence in urine of a particular antipsychotic may help to confirm compliance with prescribed medication. This will provide greater confidence (in professionals, the patient and the community) that people are being treated for their mental disorder appropriately. It is important to state that at this stage we are looking at a qualitative test for presence or absence of the drug, not a quantitative test, which may have more relevance to efficacy and effectiveness of treatment. The use of urinary testing, rather than blood testing, should generally be more acceptable to patients. It should also help to ensure that there is no confusion between periodic urinary testing for the presence of olanzapine and the routine blood monitoring that is required for potentially dangerous drugs such as clozapine.

The method currently used to screen for olanzapine involves gas chromatography/ mass spectrometry, and concentrations can be detected down to at least $100 \mu \mathrm{g} / \mathrm{l}$ using this method (I. Marsh, personal communication, 1999). Urine ( $5 \mathrm{ml}$ ) is extracted using a Toxilab extraction tube, Toxi-tube $\mathrm{A}$ (Microgen Products, Lake Forest, CA). The organic extract is evaporated to dryness under nitrogen and reconstituted in $100 \mu \mathrm{l}$ butyl acetate. The extract is then analysed by gas chromatography/mass spectrometry using a Hewlett-Packard HP6890/5973 system. Extract $(1 \mu \mathrm{l})$ is injected onto a HP-SMS capillary column $(30 \mathrm{~m} \times 0.25 \mathrm{~mm} \times 0.25 \mu \mathrm{m})$ and analysed in scan mode using a temperature program starting at $85^{\circ} \mathrm{C}$ and ramping to $280^{\circ} \mathrm{C}$ at $10^{\circ} \mathrm{C}$ per minute with a final temperature hold of nine minutes. Olanzapine is then identified by retention time and mass spectral data.

The normal elimination half-life of 32.4 hours for olanzapine should allow variable or inconsistent compliance to be detected within a reasonable period of time. The absence of clinically active metabolites further strengthens the appropriateness of the test. A mass balance study showed that approximately $57 \%$ of radiolabelled olanzapine appeared in the urine, principally as metabolites (data provided by manufacturer).

We believe we may be the first to use clinically a form of testing of urine for the presence of olanzapine. The mode of monitoring has been to discuss the situation with patients when they are in remission, to ask whether they agree to submit to random testing at various points in their community care. Obviously, patient consent can be withdrawn at any time, which may suggest that compliance is poor. If the result is positive, we have discovered that it has strengthened the therapeutic alliance between patient and doctor. We believe this is particularly valuable in cases where patients have previously shown a high degree of dangerousness when in relapse. The limitation is, of course, that quantification is not undertaken, which would mean that even very low urine levels may be detected as positive. However, as an initial first step to aiding compliance, or perhaps what is more correctly called concordance with antipsychotic medication, we believe that this form of therapeutic drug monitoring (Olesen \& Linnet, 1998) could present a major step 
forward in the management of long-term psychotic conditions in the community.

Berma, M., Shugart, R. \& Mullen, J. (1998)

Determination of olanzapine in human plasma and serum by liquid chromatography/tandem mass spectrometry. journal of Moss Spectrometry, 33, 1003-1008.

Leberman, l. (ed.) (1988) Reintegrotion of the Schizophrenic Attient, p. 51 . London: Science Press.

Olesen, O.V. Linnet, K. (1998) Determination of olanzapine in serum by high performance liquid chromatography using ultraviolet detection. fournal of Chromatography. Biomedicol Applications (Amsterdam). 714, 309-315.

Perry, P. J., Sanger, T. \& Beadey, C. (1997) Olanzapine plasma concentrations and clinical response in acutely ill schizophrenic patients. Joumal of Clinical Psychopharmacology, 17, 472-477.

Prieto, J.V. \& Hofiman, D.W. (1997) HPLC monitoring of olanzapine. Theropeutic Drug Monitoring, 19, 580.

J.W. Coates Mental Health Services, Rotherham General Hospital, Moorgate Road, Rotherham S60 2UD

\section{Olanzapine in the treatment of anorexia nervosa}

In January 1999 a 49-year-old woman with anorexia and obsessive-compulsive symptoms was admitted to hospital with an initial weight of $31.2 \mathrm{~kg}$ (body mass index 12.0 ), height $163 \mathrm{~cm}$. She had never weighed $>40 \mathrm{~kg}$. She had a 35 -year history of a severe eating disorder with several admissions in the past. Physically she was skeletal and suffered from bed sores following her inability to get out of bed unaided. Mental state examination revealed extensive obsessive-compulsive symptoms - mainly fear of food contamination, preoccupation with nutritional issues, confusion and seriously disturbed body image. She was insightless and consistently claimed that she was grossly overweight. Furthermore, she was assessed to be clinically depressed.

She was detained under Section II of the Mental Health Act 1983 (later converted to Section III). Hereafter, she agreed to voluntary food intake, which was monitored by a dietician.

She was started on olanzapine $10 \mathrm{mg}$ daily in the hope that this would alleviate her fixed perception of her own body image. It was also hoped that the unwanted effect of weight gain (Tollefson \& Kuntz, 1999) would be helpful. Because of complaints of tiredness and dizzy spells we agreed to reduce the olanzapine to $5 \mathrm{mg}$. Within a few weeks the patient became more compliant with the ward staff's daily programme of activities (increased contact with other patients, light weight-training and new routines of eating). At no point after she was started on olanzapine did she lose any weight. She had in the past tried chlorpromazine and several antidepressants without any effect.

Although still chronically ill, her mental state examinations showed continuous improvement over the following months the confusion cleared; her insight changed markedly, especially in the way she was able to link adverse early experiences to her current condition; her preoccupation with body image and food issues was less prominent and allowed her to eat suffi- ciently. Most remarkable was how the air of hopelessness and low self-esteem lifted.

On 4 July 1999 she weighed $53.1 \mathrm{~kg}$. Shortly afterwards she was discharged to a rehabilitation unit where she continues to progress.

The dramatic improvement in this patient was closely associated with the time she was started on olanzapine, but alternative/contributing factors to her recovery include a committed team effort (nurse, dietician, physiotherapist, occupational therapist, doctors), the different therapeutic environment (she was admitted out of her catchment area) and the geographical distance from her family.

It has for some time been known that olanzapine improves mood and cognition by its effects on noradrenaline and dopamine release (Bymaster et al, 1999). This patient also seemed to benefit from a much reduced pathological fear of fatness. This case report also indicates that the weightgaining propensities of olanzapine can be useful for patients with anorexia. Further research in this area could change our way of understanding and treating the increasing problem of eating disorders.

Bymaster, E., Perry, K. W., Nelson, D. L, et at (I9s9) Olanzapine: a basic science update. British fournol of Psychiotry 174 (suppl. 37), 36-40.

Tollefson, G. D. \& Kuntz, A. J. (1999) Review of recent chemical studies with olanzapine. British fournal of Psychiotry, 174 (suppl. 37), 30-35.

L. Hansen Western Community Hospital, Walnut Grove, Millbrook, Southampton SOl6 4XE

\section{One hundred years ago}

\begin{abstract}
Notes and comment
"Of the 15,000 Scotch insane, 2825, or 19 per cent, were in private families, under the excellent Scotch boarding-out system; and 2345 were supported by their own property or by friends, 15 per cent. Were those proportions made good in Massachusetts, we should now have 1600 of our 8500 insane living in families, instead of 200; and 1300 maintained by their own property or friends, instead of 1100 . In these points our State system is inferior to the Scotch; still more is the Pennsylvania system
\end{abstract}

inferior. For there, out of 10,563 insane, only 927 are privately supported, and very few are boarded in families."

Boarding-out is still a markedly successful feature of Scottish administration. Midlothian has 32 per cent of its pauper insane thus provided for; and in the parish of Edinburgh, the percentage of boarded-out patients reaches the astonishing figure of forty. If Pennsylvania has not availed herself of a good opportunity to emulate Scotland in this respect, she has made a doubtful step towards the "local custody" and maintenance of the insane under the "County-care Act" of three years ago. But overcrowding is still rife in Pennsylvania. One wonders why boarding-out does not suggest itself as a means of ready relief rather than county care.

\section{REFERENCE}

American joumal of Insonity, LVI, April 1900, 721-722.

Researched by Henry Rollin, Emeritus Consultant Psychiatrist, Horton Hospital, Epsom, Surrey 